\title{
NASOPHARYNGEAL PLASMACYTOMA WITH EXTENSIVE SKIN METASTASES
}

\author{
BY \\ D. EMSLIE-SMITH, J. M. JOHNSTONE, AND I. C. WHYTE \\ From the Department of Medicine, the Medical School and Royal Infirmary, Dundee, and the Departments of \\ Pathology and Ear, Nose, and Throat, the University and Western Infirmary, Glasgow
}

(RECEIVED FOR PUBLICATION AUGUST 5, 1954)

\begin{abstract}
Myelomatosis is not an uncommon condition, but widespread extraskeletal foci are unusual and cutaneous deposits are rare. In 1936 Aragona reported a tumour composed of plasma cells in the skin of the neck of a 6-year-old girl, with no recurrence after five years. Apart from this possible example, primary cutaneous plasmacytoma has not been described. Secondary cutaneous deposits in myelomatosis have been recorded only 16 times (Table I). Two further examples are presented here.
\end{abstract}

\section{Case Reports}

Case 1.-Early in 1943 a man aged 48 years developed pain over the left antrum and intermittent left nasal obstruction with a purulent discharge. Examination showed a polypoidal mass in the left posterior choana and opacity of the left antrum to transillumination; a left-sided ethmoidectomy and resection of turbinates was performed.

In July, 1944, the patient had a profuse left-sided epistaxis and a vascular tumour was found in the left side of the nose and left antrum. Biopsy suggested a lymphoid neoplasm. The chest was radiologically normal and radiotherapy was given to the nasal region with considerable clinical improvement.

In May, 1945, expanding osteolytic lesions of the tenth left rib and the seventh thoracic vertebra were found and irradiated.

The nasal tumour recurred in March, 1947, and was now confirmed as a plasmacytoma. Despite further irradiation both sides of the nose became completely obstructed (October, 1947). A radium pack was applied to the nose (1,000 mg. hours).

In January, 1948, the patient complained of pain in both legs and general fatigue. The nasal airway was patent, but a smooth mass was felt in each tibia and on the vertex of the skull. Radiography showed osteolytic lesions in these regions.

Laboratory investigations showed: haemoglobin 12.7 g. per $100 \mathrm{ml}$., red blood cells $4.64 \mathrm{~m}$. per c.mm., white blood cells $6,650 /$ c.mm. (differential count normal); plasma proteins $8.25 \mathrm{~g}$. per $100 \mathrm{ml}$. (albumin 4.60, globulin 3.65); no Bence-Jones proteinuria.
Shortly after irradiation of the affected bony sites the patient sustained a pathological fracture of the head of the right tibia, and $x$-ray examination showed, in addition, destruction of the distal end of the right radius and of some carpal bones. A further course of radiotherapy was given.

He was readmitted in January, 1949, having lost 1 stone $(6.38 \mathrm{~kg}$.) in a year, and complaining of pain in the right arm, left leg, and head, and a constant serosanguineous nasal discharge. Scattered in the skin of the trunk were tender, bluish-purple, or dusky-pink sessile nodules, measuring $1-5 \mathrm{~cm}$. in diameter. A course of intravenous nitrogen mustard hydrochloride (di(2-chloroethyl) methylaminehydrochloride) was administered $(28.8 \mathrm{mg}$.) with general subjective improvement, cessation of the nasal discharge, and diminution in the size of a left tibial mass.

The nasal discharge returned in May, 1949, with pain, swelling, and limitation of movement of many joints, and multiple skin tumours on trunk and limbs (Fig. 1). Widespread bony destruction was seen radiologically, especially about the ends of the long bones, and there was a pathological fracture of the upper end of the right radius (Fig. 2).

Investigation now showed: haemoglobin $12.7 \mathrm{~g}$. per $100 \mathrm{ml}$., white blood cells $6,500 / \mathrm{c} . \mathrm{mm}$. (differential count normal); serum calcium $10.4 \mathrm{mg}$. per $100 \mathrm{ml}$. (5.2 mEq. per l.), serum phosphorus $2.72 \mathrm{mg}$. per $100 \mathrm{ml}$. (1.6 mEq. per 1.), alkaline phosphatase 3.6 K.-A. units; plasma proteins $8.25 \mathrm{~g}$. per $100 \mathrm{ml}$. (albumin 4.0, globulin 4.25); E.S.R. (corrected for $\mathrm{Hb}$ ) $25 \mathrm{~mm}$. in the first hour (Wintrobe); no Bence-Jones proteinuria. Repeated marrow punctures (sternal and vertebral) did not yield cellular marrow. A skin tumour was confirmed histologically as a plasmacytoma.

After a second course of intravenous nitrogen mustard (25.6 mg.) the skin nodules regressed and the fracture united. Two courses of urethane (total $164 \mathrm{~g}$.) were then given orally. However, by September, 1949, the skin nodules were again larger and more widespread, and there was extensive destruction of the lower end of the left femur and the upper end of the left tibia (Fig. 3). The E.S.R. was $55 \mathrm{~mm}$. in the first hour (Wintrobe), and the total and differential white blood counts were normal, but the urine now contained 

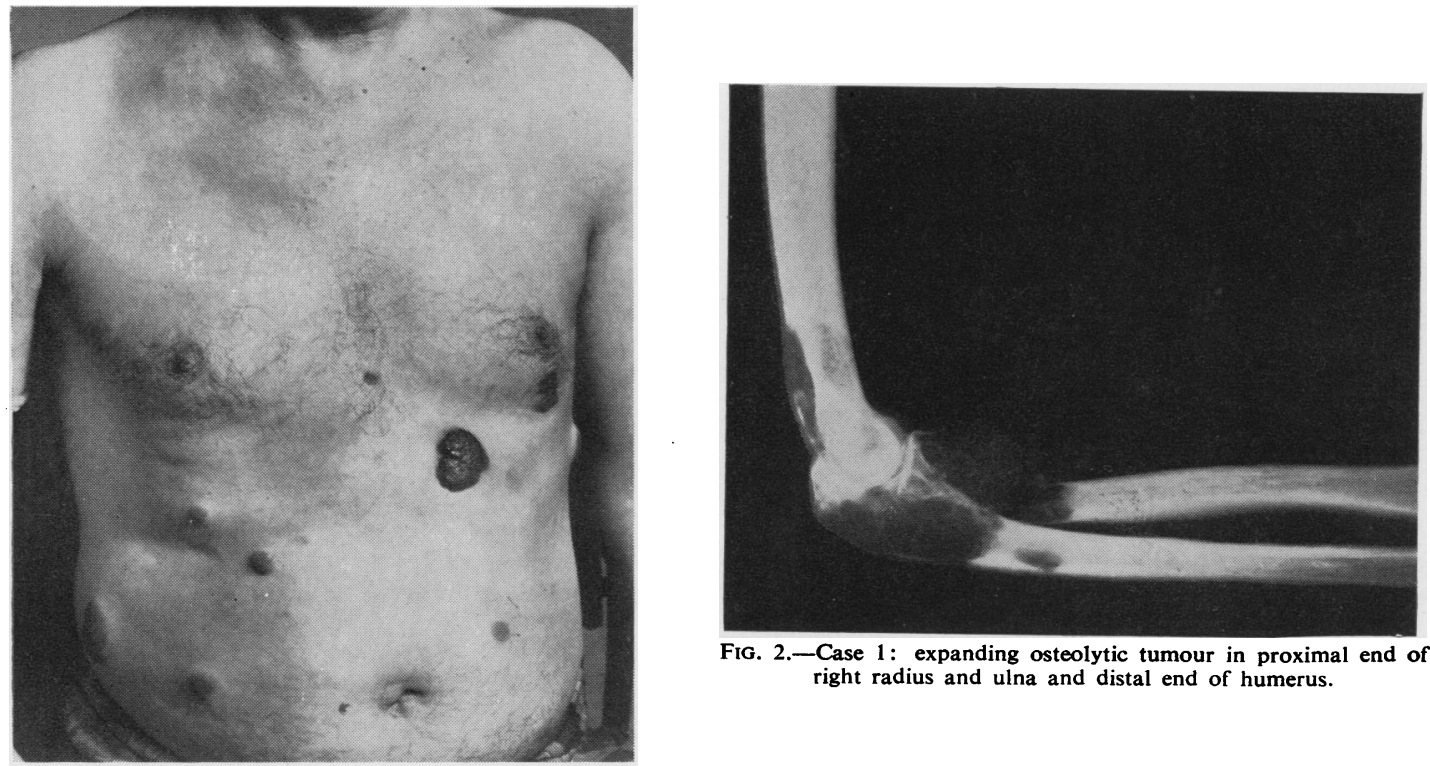

FIG. 2.-Case 1: expanding osteolytic tumour in proximal end of right radius and ulna and distal end of humerus.

Fig. 1.-Case 1: myelomatous deposits in skin of lower chest and upper abdomen.

Bence-Jones protein and the plasma proteins had risen to $10 \mathrm{~g}$. per $100 \mathrm{ml}$. (albumin 4.4, globulin 5.6). A sternal marrow aspirate showed normal haemopoiesis with no increase of plasma cells.

Despite the administration of urethane $(69 \mathrm{gg}$.$) ,$ “ R.48" ( $\beta$-naphthyl-bis ( 2 chloroethyl)-amine $(9.7 \mathrm{~g}$.$) ,$ pentamidine isethionate $(2.0$ g.) and further " R.48", $(10.5 \mathrm{~g}$.), the patient's condition steadily deteriorated. The nasal discharge returned, the skin nodules ulcerated, further bony lesions developed, and he died on February 8,1950 .

\section{Necropsy}

Numerous skin tumours, up to $6.0 \mathrm{~cm}$. diameter, were present over the trunk and lower limbs. They were raised plaques or sessile nodules, sometimes ulcerated and frequently purplish. Throughout the skeleton there were widespread, often expanding, tumours, particularly at the ends of the long bones, but the only gross extraskeletal growths, apart from those in the skin, were a small nodule above the upper pole of the right kidney and another in the pancreas.

\section{Histology}

All tumours were composed of closely packed cells in a fine reticular stroma. These rounded cells (Fig. 4) resembled primitive plasma cells, with slightly basophilic cytoplasm, sometimes with a perinuclear halo; the large eccentric nuclei contained irregularly condensed chromatin and often a distinct nucleolus. A few binucleated cells and

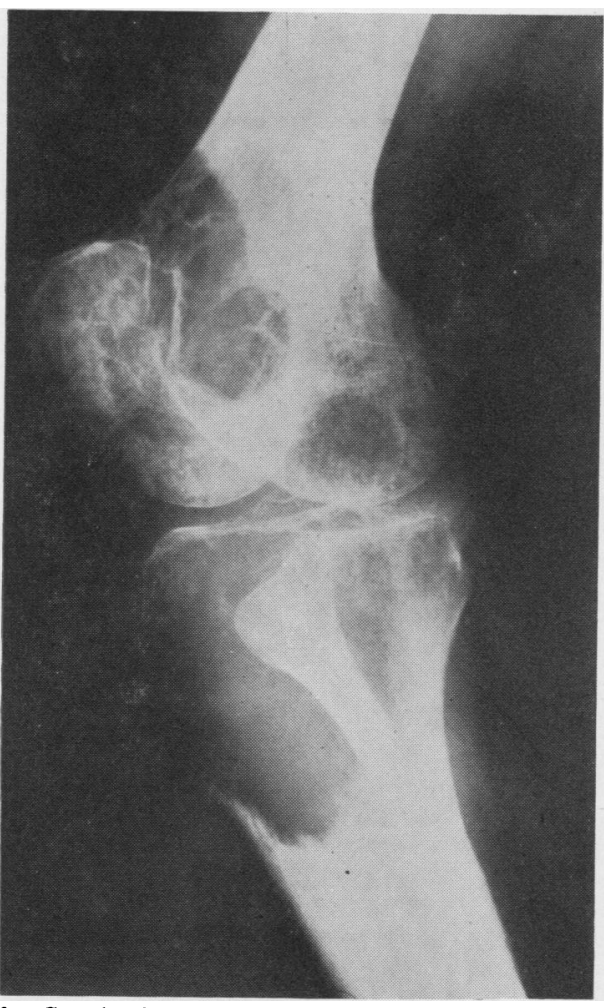

Fig. 3.-Case 1: destruction of the lower end of the left femur and head of the left tibia. 


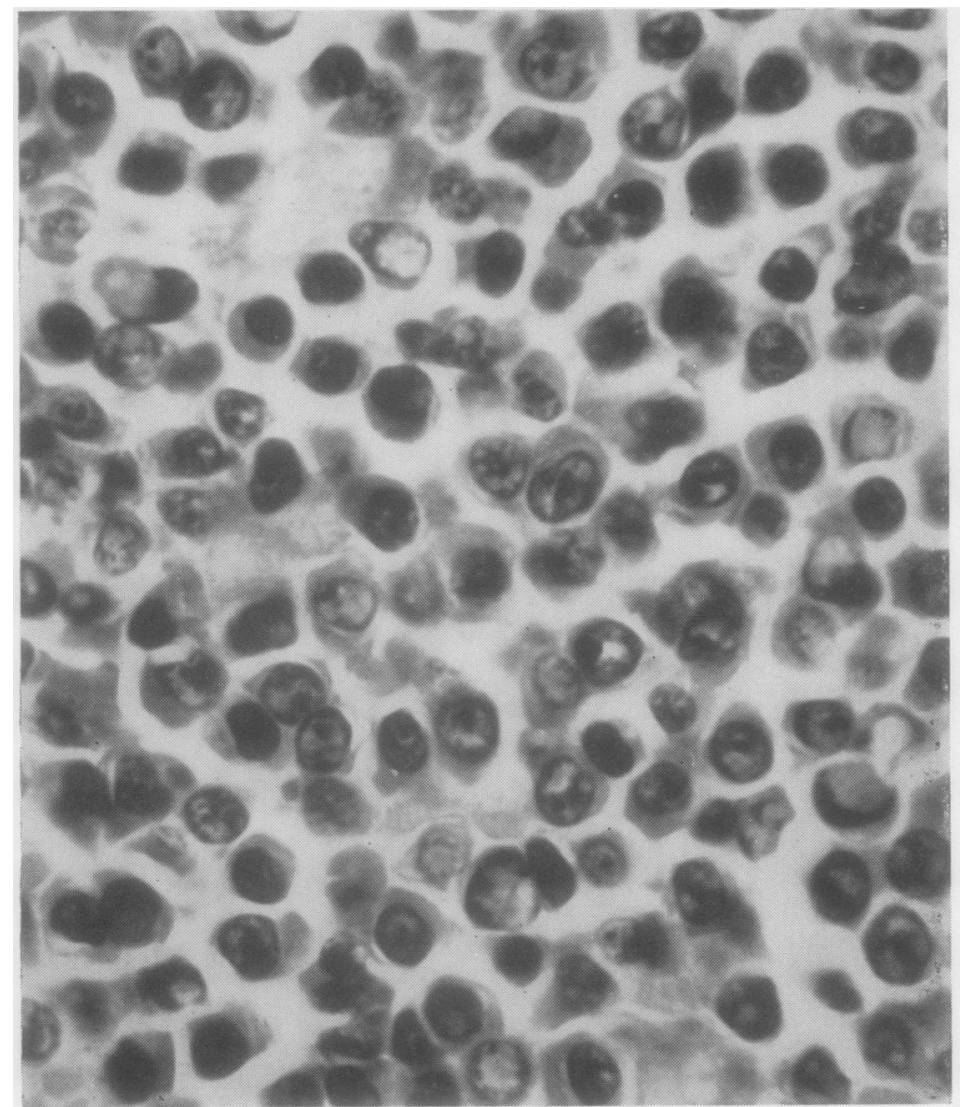

FIG. 4.-Case 1: section of a skin nodule showing the cellular detail of the growth. Haematoxylin and eosin, $\times 900$.

these areas. The patient remained well until Nay, 1953, when he complained of recent anorexia, vomiting, and pain in the right groin, hip, and shoulder. There was ptosis of the left eyelid. Over the skin of the abdomen, chest, back, and thighs there were numerous firm tumours (Fig. 5), one of which was removed and found to be composed of myeloma cells similar to those seen in the original biopsy. A normochromic anaemia ( $\mathrm{Hb} 6.3 \mathrm{~g}$. per $100 \mathrm{ml}$.) was present, but the total and dif erential white blood counts were normal and a sternal marrow aspirate showed a poorly cellular marrow with no evidence of myelomatosis. BenceJones proteinuria was not found and no osteolytic lesions were seen radiologically in the pelvis or spine.

7 he left orbital region and the skin tumours were irradiated, but the patient died ( $\mathrm{N}_{\mathrm{a}}$ ay, 1953) after bleeding during the night from a large ulcerated mass in the left thigh.

\section{Necropsy}

Numerous firm polypoid or sessile tumours, $0.5-4.0 \mathrm{~cm}$. in diameter, were present in the skin of the abdomen, chest, back, axillae, and upper thighs. They were mainly white and cellular, but others were ulcerated and necrotic, with purplish discoloration from haemorrhage. A huge, white, retroperitoneal mass, partly necrotic and

mitotic figures were seen. The skin tumours extended up to the epidermis and stretched it, enveloping and destroying appendages, with local infiltration, and a tendency to form long narrow trabeculae. There was no infiltration of the liver or kidneys.

Case 2.-A 60-year-old labourer first attended hospital in July, 1951. Previously well, he now complained of left nasal obstruction of two weeks' duration, with infraorbital pain, headache, epistaxis, and purulent nasal discharge. Vascular polypoid tissue, seen in the left antrum and ethmoid, was biopsied and found to be a plasmacytoma. There was radiological evidence of bony destruction in the left antrum, in the ethmoidal sinuses, and in the left orbit, but no other skeletal lesion was found. A sternal marrow aspirate showed no evidence of myelomatosis, there was no anaemia, the plasma proteins were normal (albumin 4.3, globulin $2.6 \mathrm{~g}$. per $100 \mathrm{ml}$.), and Bence-Jones proteinuria was not detected.

Following irradiation of the left orbital region and sinuses there was considerable bony regeneration in haemorrhagic, completely surrounded both kidneys and replaced the perinephric fat. Gross left hydronephrosis had been produced by extension of the growth into the peripelvic fat and subsequent ureteric obstruction. Many of the lymph nodes about the splenic hilum, coeliac axis, stomach, pancreas, and aorta, and in the mediastinum; axillae and inguinal regions were replaced by neoplasm, and very numerous tumours, up to $1 \mathrm{~cm}$. in diameter, were scattered in the omentum and mesentery. Single tumours were present both in the pyloric submucosa of the stomach and below the pericardium of the left ventricle. The lower lobe of the right lung was collapsed and fibrosed due to unresolved pneumonia.

The sole skeletal lesion was a pathological fracture and fusiform tumour of the right eighth rib. Red marrow filled the ribs and vertebrae, but the right femoral cavity contained gelatinous fatty marrow with mere traces of haemopoietic tissue and no evidence of myelomatosis. 


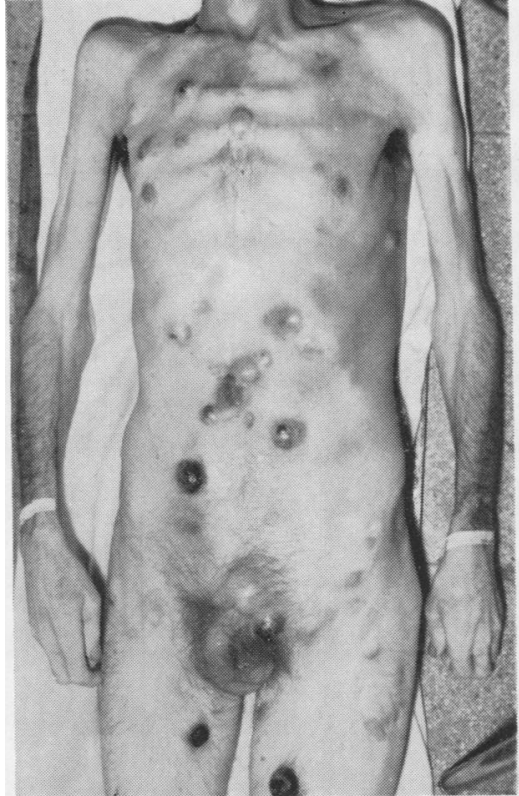

FIG. 5.-Case 2: the appearance and distribution of the cutaneous tumours. hypoplastic and gelatinous, with few mature polymorphs, and no evidence of myelomatosis.

\section{Discussion}

Our two cases show a striking similarity, although the clinical features differ in several important respects from both classical multiple myeloma and solitary plasmacytoma. In both cases the initial lesion was a soft-tissue plasmacytoma of the maxillary or ethmoidal region, followed later by the appearance of widespread cutaneous plasmacytomata and involvement, to a differing extent, of bone and lymph nodes. The marrow in both cases was poorly cellular and aspirates during life were not diagnostic. The plasma protein fractions remained normal in one case, and in the other showed the usual alterations only late in the illness, despite widespread lesions.

Extramedullary plasmacytomata are uncommon tumours, affecting males more frequently than females, and generally occurring in the mucous membranes of the upper air passages. Their histological appearance gives little clue to their future course, which varies from complete recovery

\section{Histology}

The tumours were composed of closely packed, rounded or ovoid cells with amphophilic cytoplasm and often a perinuclear halo (Fig. 6). The eccentric nuclei usually contained dense chromatin strands and often an eosinophilic nucleolus. The cells showed some variation in size and shape, with occasional multinucleated and mitotic forms, and generally resembled primitive plasma cells, the cytoplasm staining positively with the pyronin of Unna-Pappenheim's stain. The cutaneous tumours lay immediately deep to the dermal layer, extending into it and eventually ulcerating the epidermis. Occasional myeloma cells were seen in the liver sinusoids and splenic pulp, but not in the kidneys. Marrow from the sternum, vertebrae, and right femur was

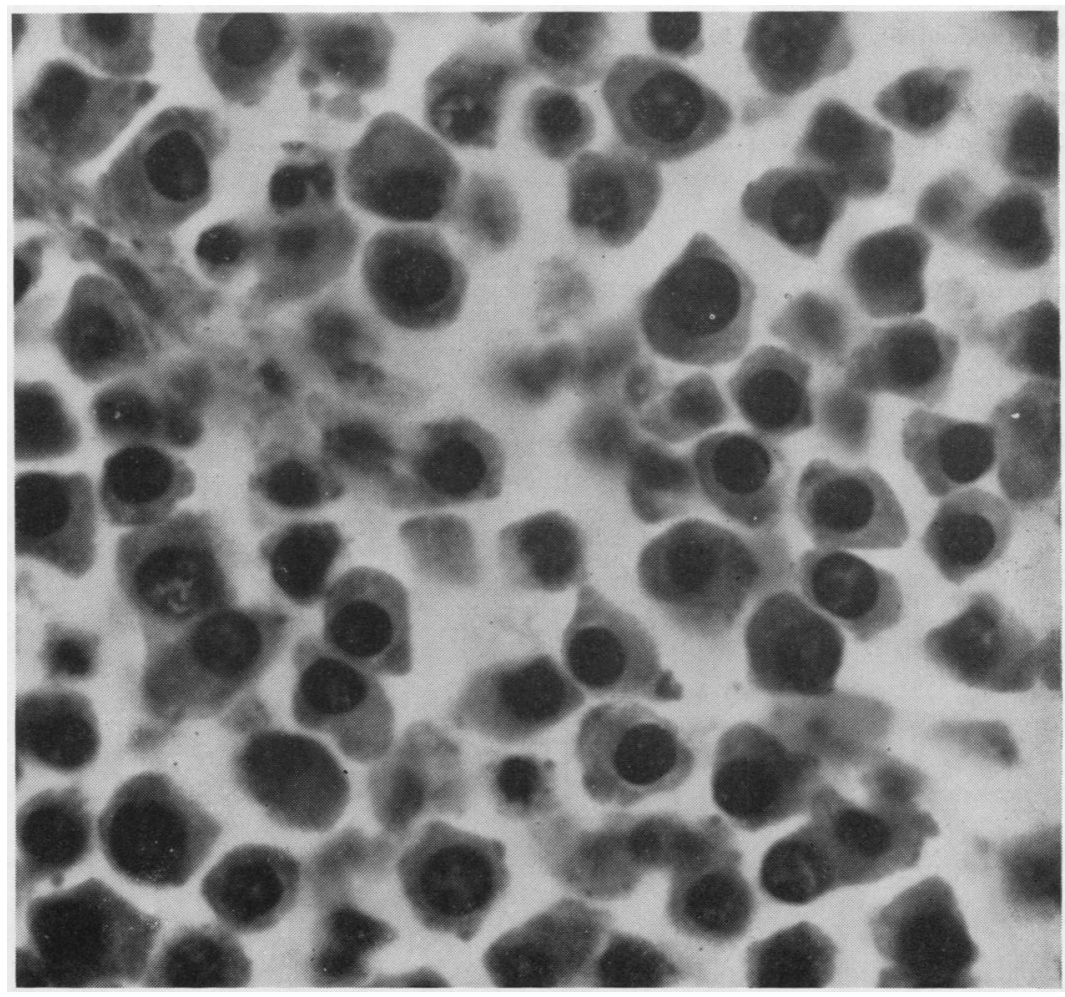

FIG. 6.-Case 2: section of the stomach nodule showing the cellular detail characteristic of all the lesions. Haematoxylin and eosin, $\times 1,400$. 
TABLE I

CASES REPORTED IN THE LITERATURE SHOWING CUTANEOUS MYELOMA DEPOSITS

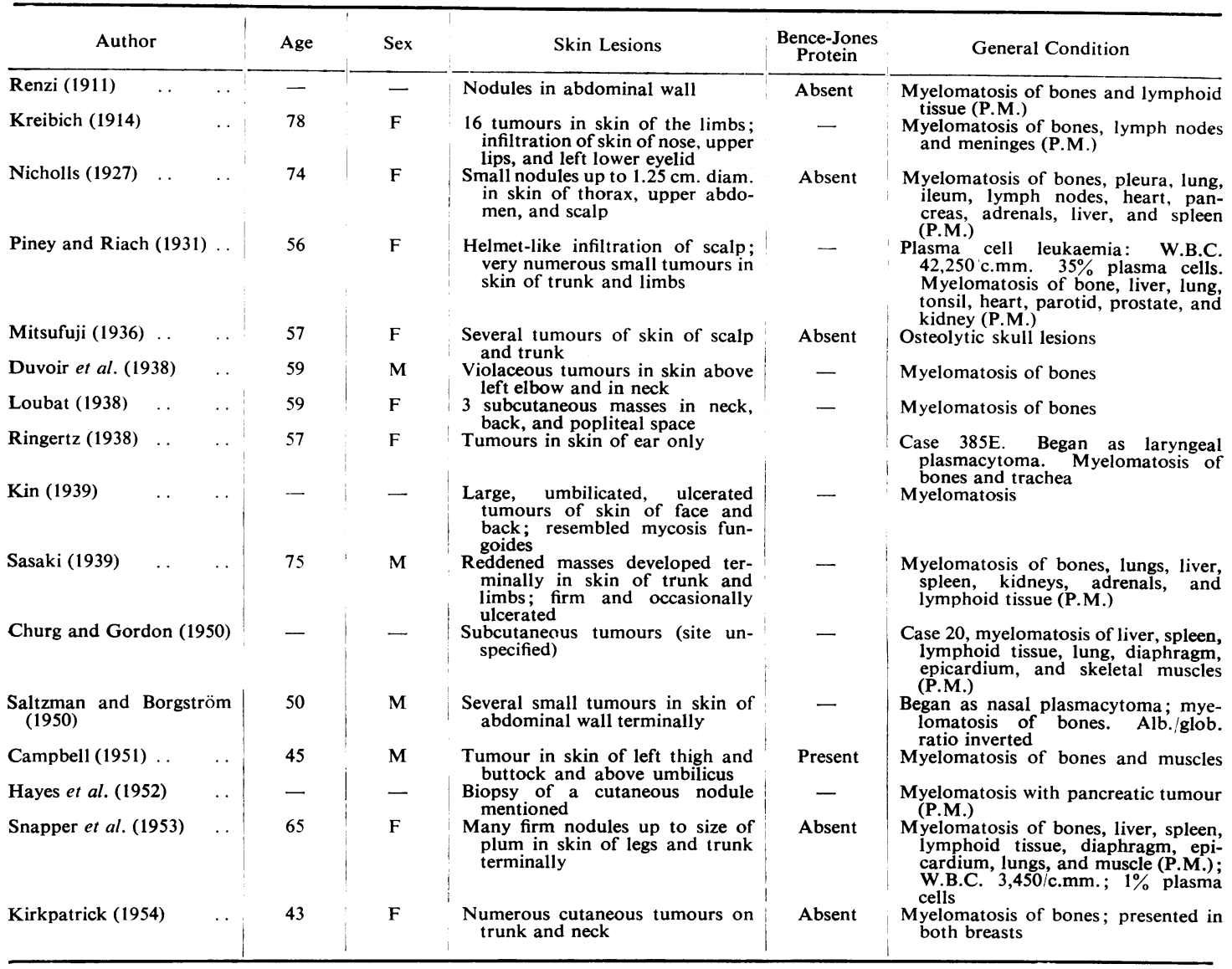

P.M. = Diagnosis confirmed at necropsy.

with treatment to the rapid or slow development of myelomatous lesions throughout the skeleton and other sites (Hellwig, 1943; Ritz and Meyer, 1952). Of the 16 cases of cutaneous plasmacytomata summarized in Table I only two originated in the nasopharynx (Ringertz, 1938; Saltzman and Borgström, 1950), the latter case being similar to our Case 1. In only one case, that of Piney and Riach (1931), was there a plasma cell leukaemia.

In Case 1 osteolytic lesions developed within two years of the appearance of the nasal growth, but the total course of the disease was protracted over seven years. At first the bony lesions were typical of those seen in myelomatosis, but later, despite a typical histological appearance, they showed an unusually pleomorphic radiological appearance with numerous, large, expanding tumours mainly confined to the ends of the long bones, and without diffuse marrow infiltration. In Case 2 the course was more rapid and the bony involvement minimal. As a general rule, extramedullary plasmacytomata and the lesions of myelomatosis respond well to irradiation early in the illness, but are later more resistant. There was a striking but transient sensitivity to various forms of treatment in both our cases: Case 1 responded well to 10 courses of radiotherapy, in addition to radium pack, nitrogen mustard, and urethane, but terminally there was no improvement with urethane, pentamidine isethionate, or "R.48."

Although gross extraskeletal tumours are unusual in myelomatosis, microscopical deposits are more commonly observed, particularly in lymph nodes, liver, and spleen (Cappell, 1929; Churg and Gordon, 1942; Lichtenstein and Jaffe, 1947; Limarzi, 1951), other sites being rarely affected. 
Apart from direct local spread there is no universal agreement on whether the disease is of multifocal origin or disseminated by metastases. Shapiro and Watson (1953) suggested that myelomatosis is a generalized disease of haemopoietic tissues, and Lowenhaupt (1945) considered it to be a diffuse lesion of the entire reticulo-endothelial system. Certainly the lesions in myelomatosis appear to have a multifocal origin in the marrow itself (Cappell, 1951), and autochthonous growth may well explain the deposits observed in such potentially haemopoietic tissues as liver, spleen, and lymph nodes.

On the other hand, metastatic blood-borne dissemination offers an alternative origin for the growths found in the lungs, skin, heart, kidneys, and elsewhere. This view is favoured by the findings of Diggs and Sirridge (1947), who observed small numbers of plasma cells in the blood in as many as 27 of 53 cases. In addition, plasma cell leukaemia occasionally develops in myelomatosis. Had we found plasma cells in the blood stream of our two cases, as did Piney and Riach (1931), we should feel more confident that metastatic dissemination explains the numerous skin deposits, but until the principles underlying metastases of malignant reticuloses are better understood we prefer to accept Willis' (1953) view that both autochthonous growth and blood-borne dissemination occur in myelomatosis.

\section{Summary}

Two cases of myelomatosis are described, each of which presented with an extramedullary plasmacytoma of the upper air passages and later developed numerous widespread cutaneous deposits. One showed unusual osteolytic tumours, while in the other the predominant feature was a widespread involvement of the lymphoid tissue with isolated deposits in bone, heart, and stomach. Both differed in important respects from classical multiple myeloma and solitary plasmacytoma.

The recorded examples of cutaneous myelomatosis are briefly reviewed.

It is probable that the extraskeletal lesions in multiple myelomatosis are both multifocal and metastatic in origin.

We are much indebted to Professor D. F. Cappell and to Professor I. G. W. Hill for their criticisms; to Dr. D. C. Wilson and Mr. I. MacGregor Seex for permission to publish and to Dr. H. J. R. Kirkpatrick for the tissues from Case 1; to Dr. J. A. W. McCluskie and Dr. F. T. Land for permission to publish Case 2.

\section{REFERENCES}

Aragona, P. (1936). Arch. ital. Anat. Istol. pat., 7, 544. Cited by Hellwig, C. A. (1943). Arch. Path., Chicago, 36, 95.

Campbell, R. T. (1951). Proc. roy. Soc. Med., 44, 408.

Cappell D. F (1929).J. Path. Bact., 32, 293.

(1951). Muir's Textbook of Pathology, 6th ed. Arnold, London.

Churg, J., and Gordon, A. J. (1942). Arch. Path., Chicago, 34, 546. (1950). Amer. J. clin. Path., 20, 934.

Diggs, L. W., and Sirridge, M. S. (1947). J. Lab. clin. Med., 32, 167. Duvoir, M., Pollet, L., Layani, F., Dechaume, M., and Gaultier, M. (1938), Bull. Soc. méd. Hôp. Paris, 54, 687.

Hayes, D. W., Bennett, W. A., and Heck, F. J. (1952). Arch. Path., Chicago, 53, 262

Hellwig, C. A. (1943). Ibid., 36, 95.

Kin, S. S. (1939). Arch. jap. Chir., 16, 79. Cited by Lichtenstein, L. and Jaffe, H. L. (1947). Arch. Path., Chicago, 44, 207.

Kirkpatrick, H. J. R. (1954). Personal communication.

Kreibich, $C$, (1914). Folia haemat $L p z, 18,94$.

Lichtenstein, (19., and Jaffe, H. L. (1947). Arch. Path., Chicago, 44, 207.

Limarzi, L. R. (1951). Med. Clin. N. Amer., 35, 189.

Loubat (1938). Bordeaux chir., 9, 36.

Lowenhaupt, E. (1945). Amer. J. Path., 21, 171.

Mitsufuji, S. (1936). Cited by Sasaki, K. (1939). Gann, 33, 171

Nicholls, A. G (1927) Canad med Ass. J., n.s., 17, 301.

Piney, A., and Riach, J. S. (1931). Folia haemat., Lpz., 46, 37.

Renzi, E. De (1911). Rif. med., $27,24$.

Ringertz, N. (1938). Acta oto-laryng., Stockh., Suppl. No. 27, p. 234.

Ritz, N. D., and Meyer, L. M. (1952). Acta haemat, Basel, 8, 224.

Saltzman, F, and Borgström, H. (1950). Acta med. Sland., 136, 388.

Sasaki, K. (1939). Gann, 33, 171.

Shapiro, H. D., and Watson, R. J. (1953). Blood, $8,755$.

Snapper, I. Turner, L. B., and Moscovitz, H. L.: (1953). Multiple Myeloma p 46. Grune and Stratton, New York.

Willis, R. A. (1953). Pathology of Tumours, 2nd ed. Butterworth, London. 